\title{
SINDROME DE GUILLAIN-BARRÉ. A PROPÓSITO DE 5 CASOS TRATADOS COM ACTH E CORTISONA
}

José Lamartine de Assis*

A. Spina França Netto **

Com base em novos conceitos patogênicos da síndrome de GuillainBarré, especialmente naqueles que incriminam a alergia como responsável pelas desordens neurológicas nesta afecção, um de nós (J. L. A. ${ }^{1}$ ) pela primeira vez em nosso meio, fêz uso de ACTH por via intravenosa no iratamento de um paciente portador de forma extremamente grave da doença em virtude do aparecimento precoce de sinais bulbares (caso 1).

$O$ efeito extraordinàriamente favorável do ACTH neste doente nos animou a utilizar o mesmo tratamento em outros casos de neuropatias alérgicas e desmielinizantes e a rever a literatura sồbre o assunto. Foram encontrados numerosos trabalhos referentes ao emprêgo do ACTH e cortisona nas afecções desmielinizantes do sistema nervoso, porém, poucas comunicações acêrca de emprêgo dêsses hormônios no tratamento da síndrome de Guillain-Barré.

Merritt $^{2}$ assinalou aparentes encurtamentos no período evolutivo de casos de polirradiculoneurite tratados com ACTH e cortisona, embora, em dois pacientes, os resultados tivessem sido negativos. Stillman e Ganong ${ }^{3}$ apresentaram um caso tratado com ACTH e cortisona por via intramuscular, tendo obtido resultados satisfatórios. Estes autores julgam que tais resultados devam ser encarados com cuidado, pois a síndrome de GuillainBarré pode variar muito na sua evolução espontânea. Seltzer e col.. ${ }^{4}$ também publicaram um caso de polirradiculoneurite com aparente resposta ao ACTH; êstes autores utilizaram $25 \mathrm{mg}$ da droga cada 8 horas pela via intramuscular; tratava-se de paciente com forma grave da doença, com sinais bulbares, e as melhoras foram muito acentuadas e rápidas 24 horas após o início do tratamento; neste caso houve remissão total. Shy e McEachern ${ }^{5}$, em estudo geral sôbre os efeitos da cortisona e ACTH nas desordens neurológicas, fazem menção a três casos de neuropatia motora periférica que não teriam sido influenciados por aquêles hormônios.

Trabalho do Serviço de Neurologia da Fac. Med. da Univ. de São Paulo, apresentado no Departamento de Neuro-Psiquiatria da Associação Paulista de Medicina, em 5 março 1953.

* Livre-Docente de Clínica Neurológica.

** Assistente voluntário. 


\section{OBSERVAÇŌES}

Caso 1 - T. B. F., homem com 37 anos, pardo, brasileiro (reg. H.C. 280346), internado em 12-8-1952. Moléstia iniciada 10 dias antes da internação, com quadro infeccioso agudo e dôres intensas nos quatro membros, seguidos, algumas horas depois, de paralisia completa dos membros inferiores e retenção de urina e fezes; a paralisia, depois de 3 dias, adotou o caráter ascendente, atingindo os membros superiores e provocando desordens na deglutição, apesar do uso de antibióticos e anti-histamínicos; finalmente, alterações cárdio-respiratórias e extraordinária acentuação das dôres. $O$ exame neurológico mostrou tetraplegia flácida, arreflexia profunda, sinais bulbares (alterações do $9^{\circ}$ e $10^{\circ}$ pares) e retenção de urina e fezes. Exames subsidiários - Liqiiido cefalorraquidiano (23-81952): punção lombar em decúbito lateral; líquiido límpido e incolor; 7 células por $\mathrm{mm}^{3}$ (linfomononucleares); $0,25 \mathrm{~g}$ de proteínas por litro; demais reações normais. Hemossedimentação (23-8-1952): $25 \mathrm{~mm}$ na primeira hora. Eletrocardiograma: achatamento da onda $\mathrm{T}$.

Tratamento - O paciente foi medicado com ACTH, sendo administrado o total de $137,5 \mathrm{mg}$, em 14 dias, por via intravenosa, dissolvidos em $500 \mathrm{ml}$ de solução glicosada a $5 \%$, durante 8 horas, gôta a gôta, nas seguintes quantidades: $20 \mathrm{mg}, 2$ dias; $15 \mathrm{mg}, 1 \mathrm{dia} ; 10 \mathrm{mg}, 5$ dias; $75 \mathrm{mg}, 1$ dia; $5 \mathrm{mg}, 5$ dias.

Evolução - Depois de uma semana as melhoras haviam sido muito rápidas e extraordinárias, a ponto de o paciente poder andar, tendo as dôres desaparecido completamente; só restava, do ponto de vista neurológico, ligeiro déficit motor nos membros inferiores. Menos de 24 horas depois de haver sido suspenso o ACTH, houve recaída, reaparecendo acentuada paresia nos quatro membros e dôres generalizadas. Punções raquidianas combinadas (lombar e suboccipital) feitas nesse momento mostraram líquores normais. Reiniciado o uso do ACTH, assistiu-se à regressão rápida e progressiva das dôres e do quadro neurológico. O tratamento foi suspenso no quinto dia depois da recaída, com remissão total da sintomatologia. Eletrocardiogramas repetidos foram mostrando melhoras progressivas das alterações do miocárdio, até completa normalização.

Caso 2 - J. M., homem com 39 anos, branco, brasileiro (reg. H.C. 265093), internado em 26-7-1952. Doença iniciada 12 dias antes da internação, com parestesias e fraqueza nos membros inferiores; uma semana depois, impossibilidade de andar e aparecimento dos mesmos sintomas nos membros superiores; parestesias na língua e desordens da deglutição; retenção transitória de fezes. 0 exame neurológico mostrou paralisia flácida dos membros inferiores com arreflexia muscular profunda; fôrça e tono muscular diminuídos nos membros superiores e reflexos musculares profundos abolidos; hipoestesia táctil nas faixas radiculares de $\mathrm{L}_{5}$ e $\mathrm{S}_{1}$ e no território dos nervos cervicais inferiores; parestesias generalizadas. Exames subsidiários - Líqüido cefalorraquidiano: em 26-7-1952, punção lombar em decúbito lateral; pressão inicial $20 \mathrm{~cm}$ de água; líquor límpido e incolor; 1,3 células por $\mathrm{mm}^{3} ; 0,50 \mathrm{~g} / \mathrm{l}$ de proteínas; reações de Pandy $\mathrm{e}$ Nonne fortemente positivas $(++)$; reação do benjoim coloidal 01210.12221 .00000 .0 ; reação de Takata-Ara positiva, tipo floculante; demais reações normais; em 27-8-1952, punção lombar em decúbito lateral; líquor límpido e incolor; 0 células por $\mathrm{mm}^{3} ; 0,30$ g/l de proteínas; reações de Pandy e Nonne positivas; reação do benjoim coloidal 00000.12221.00000.0; reação de Takata-Ara positiva, tipo floculante; em 109-1952, punção suboccipital em posição deitada; líquor límpido e incolor; pressão inicial $0 \mathrm{~cm}$ de água; 37 células por $\mathrm{mm}^{3}$ (linfomononucleose); $0,40 \mathrm{~g} / 1 \mathrm{de}$ proteínas; em 10-10-1952, punção lombar em decúbito lateral; líqüido cefalorraquidiano normal. Eletrodiagnóstico: reação de degeneração parcial nos territórios dos nervos ciático-poplíteos internos nos dois membros inferiores. 
Tratamento - O paciente foi medicado com cortisona durante 95 dias, tendo recebido um total de $5.672 \mathrm{mg}$, por via intramuscular, com dose diária administrada parceladamente, conforme o seguinte esquema: $100 \mathrm{mg}$ durante 17 dias; $60 \mathrm{mg}, 18$ dias; $40 \mathrm{mg}, 19$ dias; $24 \mathrm{mg}, 20$ dias; e $12 \mathrm{mg}, 21$ dias.

Evolução - Houve melhora progressiva; 3 semanas depois do início do tratamento, o paciente conseguia andar sem apôio, estando a fôrça muscular pràticamente normal; persistiam as parestesias nas extremidades distais dos membros, porém, a sensibilidade objetiva havia normalizado; arreflexia muscular profunda. Alta em 13-10-1952, clìnicamente curado.

Caso 3 - J. C., homem com 28 anos, branco, brasileiro (reg. H.C. 87628), internado em 27-9-1952. Moléstia iniciada de modo agudo 10 dias antes da internação, caracterizada por febre que cedeu logo, aparecendo dôres musculares generalizadas, paralisia dos membros inferiores e retenção urinária. O exame neurológico mostrava tetraparesia com hipotonia e diminuição da fôrça muscular, predominando nos membros inferiores; ataxia discreta do tipo sensitivo nos membros superiores; reflexos musculares profundos diminuídos ou abolidos; paresia facial duvidosa, do tipo periférico, à direita; papiledema bilateral. Examєs subsidiários - Líqüido cefalorraquidịano: em 29-9-1952, punção suboccipital em posição deitada; pressão inicial $15 \mathrm{~cm}$ de água; líquor límpido e incolor; 0,3 células por $\mathrm{mm}^{3} ; 0,20 \mathrm{~g} / \mathrm{l}$ de proteínas; demais reações normais; em $2-10-1952$, punção lombar em decúbito lateral; pressão inicial $32 \mathrm{~cm}$ de água; líquor límpido e incolor; 3 células por $\mathrm{mm}^{3}$ (linfócitos); $0,30 \mathrm{~g} / \mathrm{l}$ de proteínas; reações de Pandy e Nonne fortemente positivas; reação de benjoim coloidal 00000.1221.00000.0; demais reações normais; em 10-10-1952, punção lombar em decúbito lateral; líquor límpido e incolor; pressão inicial $11 \mathrm{~cm}$ de água; 3,3 células por $\mathrm{mm}^{3}$ (linfócitos); 0,30 g/l de proteínas; reações de Pandy e Nonne fortemente positivas; reação do benjoim coloidal 00000.1221.00000.0; demais reações normais. Hemossedimentação (na primeira hora): em 30-9-1952, $48 \mathrm{~mm}$ (normal, $17 \mathrm{~mm}$ ); em 210-1952, $38 \mathrm{~mm}$ (normal, $6 \mathrm{~mm}$ ); em 10-10-1952, $32 \mathrm{~mm}$ (normal, $12 \mathrm{~mm}$ ); em 24-10-1952, $17 \mathrm{~mm}$ (normal, $6 \mathrm{~mm}$ ). Eletrocardiograma: em 28-9-1952, achatamento da onda T; em 9-10-1952, achatamento da onda T e QRS levemente espessado. Eletrodiagnóstico: normal. Radiografias do tórax: em 28-9-1952, nódulos difusos, de tamanhos variados, semelhantes aos que se vêem na pneumonia reumática, em ambos os campos pulmonares; em 8-10-1952, normal.

Tratamento - Foi medicado com cortisona num total de $725 \mathrm{mg}$ em 7 dias, tendo sido usada a via intramuscular no primeiro dia e a oral nos seguintes, sendo a dose diária administrada parceladamente; no primeiro dia recebeu 300 $\mathrm{mg}$; no segundo, $150 \mathrm{mg}$; no terceiro, $100 \mathrm{mg}$; no quarto, $75 \mathrm{mg}$; no quinto, 50 $\mathrm{mg}$; nos dois últimos dias, $25 \mathrm{mg}$.

Evolução -- O paciente apresentou melhoras rápidas e extraordinárias, já notadas 12 horas após o início do tratamento; no fim da primeira semana o paciente estava clìnicamente curado, embora o líquor continuasse alterado, altera§ões essas que desapareceram algum tempo após a alta.

Caso 4 - M. N., mulher, com 24 anos, parda, brasileira (reg. H.C. 299906), internada em 15-12-1952. Apresentava, há 20 dias, parestesias nas extremidades distais dos quatro membros, de carácter ascendente, acompanhadas de fraqueza, mais intensas nos membros inferiores; desordens esfinctéricas e da fala; dôres musculares acentuadas. O exame neurológico mostrou tetraplegia flácida predominando nos membros inferiores; arreflexia muscular profunda; hipoestesia superficial nas extremidades dos membros, bem como hipopalestesia; paresia facial bilateral do tipo periférico; pontos trigeminais dolorosos. Exames subsidiários Líqüido cefalorraquidiano: em 15-12-1952, punção lombar en decúbito lateral; pressão inicial $20 \mathrm{~cm}$ de água; líquor límpido $\mathrm{e}$ incolor; 0 células por $\mathrm{mm}^{3}$; $1 \mathrm{~g}$ 
de proteínas por litro; reações de Pandy e Nonne fortemente positivas; reação do benjoim coloidal 22222.22222.22210.0; demais reações normais; em 7-1-1953, punção lombar em decúbito lateral; pressão inicial $18 \mathrm{~cm}$ de água; líquor límpido e incolor; 0 células por $\mathrm{mm}^{3} ; 0,50 \mathrm{~g} / \mathrm{l}$ de proteínas; reações de Pandy e Nonne fortemente positivas; reação do benjoim coloidal 00121.12221.00000.0; reação de Takata-Ara positiva, tipo floculante; demais reações normais; em 20-1-1953, punção lombar em decúbito lateral; pressão inicial $16 \mathrm{~cm}$ de água; líquor límpido e incolor; 0 células por $\mathrm{mm}^{3} ; 0,30 \mathrm{~g} / \mathrm{l}$ de proteínas; reações de Pandy e Nonne opalescentes; reação do benjoim coloidal 00000.122221 .00000 .0 ; reação de TakataAra negativa; demais reações normais. Hemograma: leucocitose e desvio à esquerda; linfocitose; neutrófilos com granulações tóxicas. Eletrodiagnósticc: reações elétricas anormais em vários nervos e músculos dos quatro membros; inversão polar no músculo extensor comum dos dedos à direita. Fundo de ôlho normal.

Tratamento - A paciente foi medicada com ACTH diluído em $500 \mathrm{ml}$ de solução glicosada a $5 \%$ e administrado gôta a gôta na veia por período, de 8 horas, diàriamente. A dose total foi de $245 \mathrm{mg}$, assim distribuída: $20 \mathrm{mg}$ por dia, uma semana; $10 \mathrm{mg}$ por dia, uma semana; $5 \mathrm{mg}$ por dia, uma semana.

Evolução - As melhoras foram lentas, mas progressivas na primeira seınana e rápidas a partir do início da terceira semana. Vinte dias depois do início do tratamento a paciente começava a andar e no fim do primeiro mês se locomovia com facilidade e de nada mais se queixava. Alta, curada, após 35 dias de internação.

Caso 5 - F. K., mulher com 49 anos, branca, alemã (reg. H.C. 67799), internada em 13-5-1953. Moléstia iniciada de modo rápido no fim de dezembro de 1952, caracterizando-se por diminuição acentuada da fôrça muscular dos membros, maior nos inferiores, não se podendo locomover ou ficar de pé; dôres musculares; desordens esfinctéricas. Foi internada no hospital em enfermaria de clínica médica, onde foi medicada com vitamina $B_{1}$, não tendo melhorado; teve alta um mês depois, sendo então internada na enfermaria de Neurologia. Nesta ocasião o exame neurológico mostrou acentuada paresia dos quatro membros, predominando nas suas porções proximais, com diminuição da fôrç̧a e do tono muscular; reflexos musculares profundos normais, com exceção dos reflexos patelares e do aquiliano direito, que se achavam abolidos; moderada atrofia dos músculos das pernas, atrofia mais acentuada dos músculos das mãos. Exames subsidiários - Líqüido cefalorraquidiano: em 9-3-1953, punção lombar em decúbito lateral; líquor límpido e incolor; 0 células por $\mathrm{mm}^{3} ; 0,40 \mathrm{~g} / \mathrm{l}$ de proteínas; reações de Pandy e Nonne positivas; reação do benjoim coloidal 00000.12221.00000.0; demais reações normais. Eletrodiagnóstico: síndrome elétrica de degenerescência parcial no território muscular dos nervos cubital (punho) e mediano (punho), bilateralmente, e dos nervos cubital (cotovêlo) à direita e ciático-poplíteo externo à esquerda. Reações elétricas anormais quantitativa e qualitativamente no músculo flexor superficial dos dedos, bilateralmente; hipoexcitabilidade farádica e galvânica nos demais nervos e músculos examinados. Hemossedimentação (na primeira hora): em 6-3-1953, $21 \mathrm{~mm}$ (normal, 12); em 30-3-1953, $12 \mathrm{~mm}$ (normal, 12).

Tratamento - Foi medicada com ACTH diluído em $500 \mathrm{ml}$ de soluto glicosado a $5 \%$ e administrado por via intravenosa (gôta a gôta) durante 8 horas diàriamente. Dose total de $119 \mathrm{mg}$, em 15 dias, assim distribuída: 12,5 mg, 3 dias; $10,0 \mathrm{mg}, 2$ dias; $8,0 \mathrm{mg}, 3$ dias; $5,0 \mathrm{mg}, 7$ dias; $2,5 \mathrm{mg}, 1$ dia.

Evolução - A paciente apresentou melhora do quadro neurológico até então estacionário. Doze dias após o início do tratamento podia ficar de pé e começou a andar. Alta, melhorada, 25 dias após a internação, andando de modo satisfatório e sem apôio. 


\section{COMENTARIOS}

Embora os resultados devam ser encarados com prudência, parece que os hormônios glicocorticóides têm ação benéfica nas polirradiculoneurites, pois houve nítido encurtamento do tempo de evolução clínica nos casos referidos, e coincidências indiscutíveis entre as remissões e o emprêgo dos medicamentos. $O$ curso da afeç̧ão habitualmente é prolongado, considerando Brain ${ }^{6}$ que ela se processa entre 3 e 6 meses; esta longa evolução é também assinalada por outros autores ${ }^{7}$. Nos casos que observamos houve remissão e alta hospitalar em menos de 40 dias de tratamento, com exceção do caso 2 , onde uma intercorrência não o permitiu. No caso 1 foi observada a relação íntima entre a remissão e o uso do ACTH; a recaída se verificou menos de 48 horas depois de suspensa a droga, porém, foi seguida de nova e definitiva remissão com o reinício do tratamento. Não ocorreu óbito, embora em um dos casos houvesse sinais de sofrimento bulbar (caso 1). Roseman e Aring ${ }^{8}$ e Brain ${ }^{6}$ assinalaram a morte em $20 \%$ dos casos de polirradiculoneurite, nos primeiros 15 ou 30 dias, por paralisia respiratória. Segundo Stillman e Ganong ${ }^{3}$ e outros, a remissão espontânea rápida é excepcional. A remissão precoce obtida em quase todos os nossos casos por ação do ACTH e cortisona depõe em favor das idéias mais atuais sôbre a patogenia da síndrome de GuillainBarré. Nestes estudos ${ }^{9}$ tem sido salientado que o edema das raízes nervosas constitui alteração primária e é seguido de desmielinização e destruição do axônio sem lesões inflamatórias agudas. A causa do edema é obscura; Haymaker e Kernohan fizeram menção à queda rápida das proteínas no líqüido cefalorraquidiano por efeito do tratamento hormonal, mostraram a elevada hemossedimentação associada à doença e aceitaram a patogenia alérgica desta, com edema e congestão das raízes espinais. $\mathrm{Na}$ presente série não foi possível comprovar a queda rápida das proteínas do líquor; nos pacientes em que foi verificada a hemossedimentação, ela se ąpresentou elevada; no caso 3 , a sedimentação baixou de 48 para $17 \mathrm{~mm}$ em menos de um mês de tratamento. Neste particular o material não permite, ainda, conclusões definitivas.

Os dados apresentados referentes a êsses 5 casos permitem estabelecer que o ACTH e a cortisona representam, no momento, os melhores recursos terapêuticos para o tratamento da síndrome de Guillain-Barré, especialmente em suas formas mais graves. Os resultados obtidos vêm em apôio da teoria alérgica, que procura explicar a patogenia da doença, justificando sua inclusão no grupo das afeç̧ōes desmielinizantes do sistema nervoso, conforme já foi salientado por um de nós (J. L. A. ${ }^{1}$ ).

RESUMO

São registrados 5 casos de síndrome de Guillain-Barré (polirradiculoneurite) tratados com ACTH ou cortisona. Foi observada melhora rápida 
em todos êles, em tempo variável de um para outro caso, mas menor que o tempo médio de evolução da moléstia quando tais hormônios não são empregados. Em vista da evolução observada é discutida a teoria da patogenia alérgica da doença e sua inclusão no grupo das doenças desmielinizantes do sistema nervoso.

\section{SUMMARY}

Five cases of Guillain-Barré' syndrome treated with ACTH or Cortisone are reported. Rapid improvement of the symptoms occurred in all cases. The time of evolution in these cases was shorter than that commonly observed when the disease was not submitted to this therapy. The shortening of the evolution when the disease is treated with ACTH or Cortisone supports the allergic theory on its pathogeny, as well as its inclusion among the demyelinating diseases of nervous system.

\section{BIBLIOGRAFIA}

1. Assis, J. L. - Síndrome de Guillain-Barré. A propósito de três casos, sendo um tratado pelo ACTH. Arq. Neuro-Psiquiat., 11:133-144 (junho) 1953. 2. Merritt, H. H. - Corticotropin and cortisone in diseases of the nervous system. Yale J. Biol. a. Med., 24:466-473 (junho) 1952. 3. Stillman, S. J. e Ganong, F. W. - The Guillain-Barré syndrome: report of a case treated with ACTH and Cortisone. New England J. Med., 246:293-296 (21 fevereiro) 1952, 4. Seltzer, H. S., Lichty, D. E. e Conn, J. W. - A case of Guillain-Barré syndrome (infectious polyneuritis) with apparent response to ACTH. Univ. Michigan M. Bull., 18:27-31 (janeiro) 1952. 5. Shy, G. M. e McEachern, D. - Further studies of the effects of Cortisone and ACTH on neurological disorders. Brain, 74: 354-362 (setembro) 1951. 6. Brain, W. R. - Diseases of the Nervous System, ed. 3. Oxford University Press, Nova York, 1947, págs. 795-798. 7. a) Jones, J. A., Holmes, J. W. e Weinstein, M. - Acute infectious polyneuritis (GuillainBarré syndrome). Am. J. M. Sc., 206:305-309, 1943; b) DeJong, R. N. - Guillain-Barré syndrome: polyradiculoneuritis with albuminocytologic dissociation. Arch. Neurol. a. Psychiat., 44:1044-1068, 1940. 8. Roseman, E. C Aring, C. D. - Infectious polyneuritis. Medicine, 20:463-494, 1941. 9. a) Haymacker, W. e Kernohan, J. W. - Landry Guillain-Barré syndrome. Medicine, 28:59-141, 1949; $b$ ) Pullin, R. L. e Sodeman, W. A. - Infections polyneuritis (Guillain-Barré syndrome). Am. J. M. Sc., 211:110-122, 1946.

Clínica Neurológica - Hospital das Clínicas - São Paulo. 